\title{
Sustainable Development in Damascus University: A Survey of Internal Stakeholder Views
}

\section{Environmental Studies}

\begin{abstract}
Keywords: Sustainable development; Pedagogy; Analytic network process; Syria; Planning

Abstract

In our days, the sustainable development concept has trendy become a necessity in pedagogy. The campus is not only a fashion of an engineering design but also a place for sustainable learning put into practice. In view of the fact that the United Nations Declaration on the Environment focuses on the concept of sustainability in higher education since 1972 considering a sustainable campus formulation which has been increasingly attracting international attentions. This research tries to profoundly observe the evaluation of the sustainability of a campus taking Damascus University as a case study. Semistructured interviews with key informant stakeholders were executed to define critical factors of sustainable campus development. The weightings of these key factors were established by using the analytic network process method. These findings were provided useful inputs for future endeavors of sustainable university development which would contribute towards responses to rapid urbanization.
\end{abstract}

\section{Introduction}

The higher education sector plays a significant role in achieving a more sustainable future as students become future leaders, technical staff or the backbone of social work depending on what they learned will directly affect their future decisions on social sustainable development (SD) [1]. It is not unusual that university campus occupies considerable land at either urban or regional areas. Moreover, universities play an important role in our society in terms of sustainable technology studies providing opportunities tackle environmental issues. Sustainability initiatives have been taken up by an increasing number of colleges and universities around the world [2] so many universities bear obligations to contribute toward SD [3].

The Stockholm Declaration (1972) was the first attempt introducing principles of SD into the higher education sector. This was followed by constant efforts and initiatives such as the Talloires Declaration (1990), the Halifax Declaration (1991), the Association of University Leaders for a Sustainable Future (ULSF) (1992) and the Swansea Declaration (1993). Along with a broader coverage of topics ranging from campus operation to community engagement, all these Declarations and Initiatives served similar purposes, i.e. promoting the development of sustainable campuses [4]. In addition, a growing number of universities over the world have signed these international declarations that are then reflected in the sustainability initiatives [5].

As an example in this connection, the Syrian government has released a number of policies to promote SD in the higher education sector. As specified in the Program of Action for National Environmental Publicity and Education, higher education institutions are encouraged to implement green university initiatives, e.g. incorporating environmental sustainability into curricula. A series of technical guidelines and management measures were released in

\section{Loai Aljerf ${ }^{1 *}$ and Ala Eldin Choukaife ${ }^{2}$ \\ ${ }^{\prime}$ Department of Life Sciences, Faculty of Dentistry, University of Damascus, Damascus, Syria \\ ${ }^{2}$ Department of Life Sciences, Faculty of Dentistry, Syrian Private University, Damascus, Syria \\ *Address for Correspondence \\ Loai Aljerf, Department of Life Sciences, Faculty of Dentistry, University of Damascus, Damascus, Syria, Tel: +963 944482 203; E-mail: envirochrom@hotmail.com \\ Submission: 18 July, 2016 \\ Accepted: 12 August, 2016 \\ Published: 17 August, 2016 \\ Copyright: (ㄷ 2016 Aljerf L, et al. This is an open access article distributed under the Creative Commons Attribution License, which permits unrestricted use, distribution, and reproduction in any medium, provided the original work is properly cited. \\ Reviewed \& Approved by: Dr. Mark Meo, Department of Geography \& Environmental Sustainability, University of Oklahoma, USA}

order to facilitate this process. These include opinions on promoting the resource efficient campus development (energy and water saving) in higher education institutions, technical guidelines for the construction of the energy conservation monitoring system in higher education institutions, and technical guidelines for the operation management of the energy conservation monitoring system in higher education institutions.

Certain assessment methods have been developed for evaluating campus sustainability that covers five major aspects of campus sustainability, i.e. governance, campus planning, energy efficiency and environmental protection technologies, energy efficiency monitoring and campus culture $[6,7]$.

Accordingly, the Declaration is necessary being proposed in Syrian universities that harmonizes humans and natures, cultivates students' awareness of SD in responsible manner, and constructs itself into a model community with a resource-saving system, sustainable environment and virtuous ecology circle. However, there are comparatively limited studies focusing on establishing an evaluation system of a sustainable campus in this context.

On the result, this paper comes to describe a research with the following objectives:

A. To assess current understanding of sustainable campus development;

B. To investigate the critical factors for sustainable campus development; and

C. To identify relative importance of these factors and propose recommendations on sustainable campus construction.

\section{Literature Review}

According to Mcmillin and Dyball, most universities over the world take an ad hoc approach to deal with sustainability issues 
in higher education, i.e. teaching and research are isolated from university operation [1]. The university is a complex system consists of a number of components, so an integral approach is required $[8,9]$. Brown proposed an integral approach of SD consisting of four quadrants that are divided by two factors, i.e. internal vs. external and individual vs. organizational [10]. This presents a simple way to organize the innumerable subjective and objective dimensions of individuals, societies, and the environment. Schild introduced some elements to this quadrant system in order to evaluate sustainable campuses, which incorporated four sections i.e. psychological influences, behavioral influences, cultural influences, and system influences [11]. However, there is still a lack of a better understanding of how to build a sustainable campus through teaching, research, extension community, university administration, etc. [12,13].

Alshuwaikhat and Abubakar pointed out that the sustainability practices in universities together with university Environmental Management System (EMS), public participation and social responsibility, sustainability teaching and research have both soft factors (e.g. public participation and teaching) and hard factors of a campus (e.g. transportation and campus planning) $[14,15]$.

However, there is generally a lack of empirical study of campus sustainability in a Syrian context. The Sustainable Endowments Institute (SEI) suggested that there are 8 aspects associated with sustainable campus evaluation, i.e. administration, climate change and energy, food and recycling, green buildings, student involvement, transportation, endowment transparency, investment priorities and shareholder engagement [16]. Since 2008, a new component, student involvement was added and compared to previous versions. Sustainable campuses consist of various buildings; therefore, it is imperative for all of these facilities to be sustainable. These include construction of the green buildings $[17,18]$, alternative forms of transportation [19], waste recycling [20,21], and reduction of the resource consumption [22,23]. In addition, sustainable campus should consider the control of room temperature and humidity [24]. The most common metrics in these aspects include greenhouse gas emissions, carbon footprint, and environmental load.

To evaluate green buildings, Leadership in Energy and Environmental Design (LEED), established by the U.S. Green Building Council has been launched in 2003, is a practical tool. This system includes various aspects of the building's location, water use, energy and atmosphere, materials and resources, indoor environmental quality, innovation and design. In 2008, the U.S. Green Building Council released a set of green building evaluation for new campus buildings that offered major renovation of buildings for Schools New Construction and Major Renovations Rating System [25].

Apart from technical aspects, management associated factors are critical for achieving campus sustainability. Cultural values and cultural environment are essential to sustainability [20]. Cole has developed a system, called: Campus Sustainability Assessment Framework (CSAF) to evaluate sustainable campuses which includes the aspects of education, management and planning [26]. On the basis of this system, the Association for the Advancement of Sustainability in Higher Education (AASHE) developed a tool called the new Sustainability Tracking, Assessment and Rating Tool (STARS) to evaluate sustainability in higher education sectors, which covers similar aspects such as: education, management, and planning [27].
In terms of management mechanism, Lukman and Glavič proposed that constructing a sustainable campus needs to build a suitable management system [28]. This management approach can be either top-down, bottom-up, or hybrid [29].

Meanwhile, coordination between various subsystems of a university is crucial for sustainable development in higher education [30]. Sarah and Too and Bajracharya further pointed out the critical role of engaging shareholders into campus sustainability decisions [31,32]. However, in Syria, shareholders are not involved in this context in the academic institutions whether in the public universities or even in the junior private ones. The private universities have in general fragile education systems due to their novelties where most of them have been established in the last quarter of the 20th century and at the beginning of the 21 st century.

Mcmillin and Dyball proposed an innovative management approach, i.e. establishing an education management system such as a university town for sustainable higher education where it provides students more exposure to SD [1]. EMS serves as a monitoring mechanism of sustainability practices and performance in universities [33]. Based on EMS, environmental auditing and accounting can be undertaken [34]. To achieve campus sustainability, universities and colleges can choose a top - down or bottom-up approach [35]. Both approaches have advantages and disadvantages, therefore it is essential to take an integrated approach [36].

For the education aspects of a sustainable campus, Rands asserted that campuses should emphasize the awareness of students on sustainability, and further suggested that campuses cultivate their knowledge, attitude and technology on SD [37]. Lüdeke-Freund and Burandt proposed a novel learning system based on three organizational learning models that shift the paradigm from what to learn and to how to learn [38]. Hall and Mooney suggested nonconventional approaches as distance learning, which can diversify tertiary education and make the methods of learning more suitable for the globalization [39].

In the Middle East, there are few programs working on the investment of SD concepts as:

I. Education for Sustainability Development Beyond the Campus (EduCamp) (http://schools.aucegypt.edu/Sustainability/CSD/Pages/ EduCamp.aspx) which develops teaching and learning toolkits, and teacher's guides on education for sustainable development (ESD) at all levels of general education in Egypt. As well as, it conducts training of instructors who subsequently held training sessions for teachers on applying these toolkits in the classroom;

II. Sustainable Education Program through Renewable Energy in Jordan - Majesty King Abdullah Bin Al-Hussein Initiative 2015 (Available at: http://kingabdullah.jo/index.php/en_US/initiatives/ view/id/12.html (or) http://www.masdar.ae/en/media/detail/ jordans-king-abdullah-ii-inaugurates-first-utility-scale-wind-farmin-the-m) which aims to install and operate solar energy modules to generate electricity in the schools of the Ministry of Education, so as to reduce conventional energy costs in schools. In addition, this project develops practical educational programs to provide students with the knowledge and skills that promote efficient water use and provide safe and healthy water in the targeted schools; 
III. Gulf Environment Portal Project - involves environmental cleaning aspect and future/planned environmental program presented for smart classrooms. In specific, this proposes e-learning model which has been utilized to implement the national e-learning strategy in the Ministry of Education of Kuwait since 2015 [40];

IV. My Responsibility in the Face of Climate Change - The Tunisian project that aims to promote environmental awareness and environmental-friendly behaviors among students. This develops strategies for climate change mitigation, strengthens the role of students in addressing the negative impacts of climate change in the surroundings (neighborhood, school, and home) through engaging them as active stakeholders in climate change awareness projects and educating junior high school students on climate change issues [41]; and

V. Green Light Project sponsored by the Syrian Society for Conservation of Wildlife (SSCW) (http://www.birdlife.org/middleeast/partners/syria-syrian-society-conservation-wildlife-sscw), that created non - formal learning methods directly affect the development and evaluation of children's skills on themes relating to climate change, sustainable and environmental issues. This project had established training programs to increase teachers' knowledge of various kinds of environmental issues, especially local environmental challenges, and directed also to provide them with all the necessary tools, concepts and skills that would help trainees to effectively contribute to their communities. In this program, students were strengthened their leadership skills in the field of environmental preservation and SD through linking intra - and extra - curricular educational activities.

In the Syrian context, the awareness of the importance of the sustainable education on the higher political levels and the wider community is based on the reality that students will become leaders in their chosen professions. This enables the university to use its resources more wisely and economically, without sacrificing comfort or convenience. Less energy, fuel, food and materials will be wasted on campus and more resources will be available for creating and delivering innovative educational programs and quality work environments for all. Significantly, students would be provided up-todate opportunities for professional training and growth in sustainable practices as relevant to their professions. Hereby, sustainable education recognizes that the whole educational system should maintain the benefit, so that students can be offered a satisfied environment with education and practice. This has significant implications to curricula, e.g. introducing general sustainability related courses in the sophistry years, developing trans-disciplinary courses on sustainability issues and sustainability oriented student practice sessions. As a result, it will later drift SD concepts and principles into the Syrian curricula.

\section{Background}

Syria has traditionally been limited to the negative impact of region's fossil fuel exports on climate change and addressed in an area's water scarcity, rapid urbanization, environmental degradation, and the expected impact of global climate change and sea level rise.

This country represents a society in transition, where a fundamental change is taking place. This change concerns economic, industrial and societal transformation and last but not least those of Syria's educational system, particularly regarding its higher education. The socio-economic conditions have produced urbanisms that are radically different and equally unsustainable.

Sustainability is a process that can be characterized by a certain socio-ecological ideal and often linked to environmental goals of ensuring that resources are used in a costly and effective way as to minimize both waste and damage. Much as many may think that Asian countries have nothing good that the biblical histories, Syria has been on the rise as far as foreign attraction is concerned. Before the Syrian crisis, many people have come to visit the country for tourism reasons or just for holidays. The cost of living and studying here were affordable.

For free learning world, Bell and Ramadan showed that Syrians had used challenging strategies which could really shake up the Ivory Tower and offers minds in all places globally the hope of quality education irrespective of income, culture or gender and further had verified Syrians acceptance of digital lectures after 5 years of their country crises $[42,43]$.

Ministry of Higher Education (MoHE) in Syria has a high coordination with many regional associations as Mohammad Bin Rashid Al-Maktoum Foundation, Arab Council for Higher Studies and Scientific Research, Arab Council for Training of Arab Universities, the Council of Quality Assurance and Accreditation, and Council of Arab Ministers responsible for the environment of educational issues which enhances the awareness and knowledge on environment and development issues in all Arab countries and strengthens these contributions through regional and international cooperation. In addition, MoHE is a part of the project: Development of a Higher Education and Research Area between Europe and the Middle East (HERMES, 2013 - 2017). The project is coordinated by Aix-Marseille University/Tethys Network and involves 20 partner universities - 11 from the Middle East (Jordan, Lebanon, Syria, and Palestine) and 9 from the EU. The objectives are to develop higher education teaching and learning capacity through the transfer of know-how and knowledge; to improve the employability of the individuals by giving them the appropriate skills as regards to the labor market and an international experience in the context of globalization.

Syrian open learning is concerned with two of great issues of our time: Firstly, sustainability, including the qualities and availability of higher education in a global setting - this setting being globalization the importance of which was made manifestly clear in the recent cut and thrust evident at the $21^{\text {st }}$ conference of the Parties to the United Nations Framework Convention on Climate Change (COP21) deliberations in Paris in December 2015. Secondly, the disruptive technologies which are on the one hand providing the global learning community with the potential for more and more access to the wisdom of world scholarship and yet, on the other hand are disrupting the very models which are attempting to deliver this learning.

Howbeit, DU has strong inter-university cooperation with international institutions by the investment of such international programs like Tempus and Erasmus Mundus but weak within the country. Competition with other private institutions is weak which makes it reluctant to cooperate. DU has a long history of engaging 


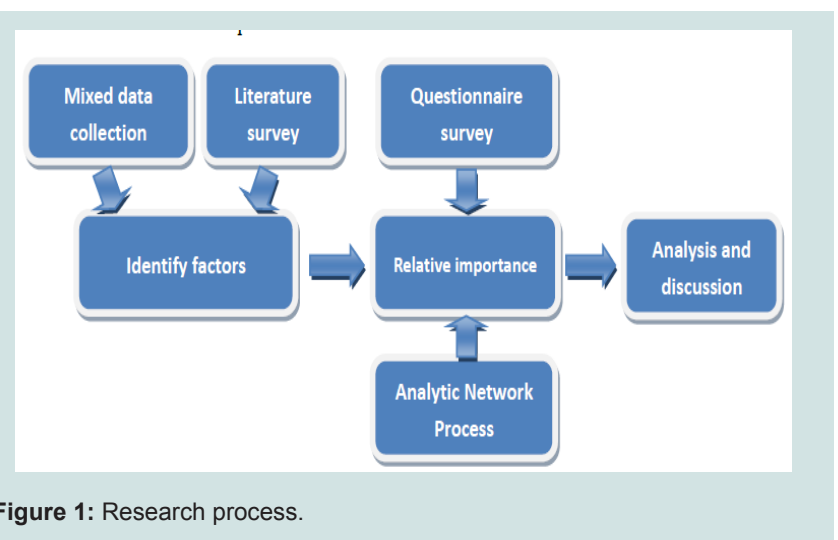

students, faculty and staff on issues of environmental stewardship both in and outside the classroom using the most effective technical education programs (i.e. desertification, impacts and risks of climate change, disaster risk management courses) tailored towards developing green skills and professions. The university has established different useful local partnerships with the Ministry of Environment and Ministry of Education in order to create forward - looking visions that include all dimensions such as environmental, social and educational, foreseeing scientific issues and features of progress, adopting e-learning and developing scientific curricula, promoting knowledge on climate change and subsequent modification in behaviors, and exchanging experiences among other regional organizations and international higher institutes.

Recently, after the Regional Experts Meeting on Climate Change Education for Sustainable Development in the Arab States that held in Beirut, 5 - 7 May 2015 and in order to move DU toward the goal of climate neutrality, the university has formulized institutional efforts at sustainability with the creation of the central office of Campus Sustainability follows the College of Education at DU, within Campus Operations. Nowadays, all the efforts are assigned to activate the principal "Education for Mitigation" in DU which is supported by other sustainable schools and other national campuses that serve as learning laboratories for students to demonstrate and further deepen the understanding of the principles learned in the classrooms. As a consequence, the studies in DU that work on improving sustainability issues and quality climate change education for SD have the opportunity to upload their recent findings on the websites of UNESCO through the Global Action Program (GAP) on ESD.

\section{Research Methodology}

Very little is actually known about the success or failure of admission criteria of sustainability in Damascus University (DU) campus, in which they may shape the attitudes, progress, and performance of students throughout their years of study. The lack of measurable data on admission policies and their consequences indicate an urgent need for in - depth investigations in this area.

The study involves in-depth case study of the campus sustainability practices in DU (Figure 1). Mixed data collection approach was adopted in this case study. Semi-structured interviews with keypersonnel participation in SD of DU were conducted, in order to, identify key factors contribution or impeding sustainable campus development. Apart from in-depth interviews, these were held in charge of the direction of the campus construction. Some university official documents had been accessed and reviewed, in order to, replenish the key factors. To analyze data, a similar approach to Chen et al. was also used, i.e. forming a set of categories of conceptions focusing on distinctive features [44].

The reason to choose DU was because it has a historic national campus and a leading university works directly under the leadership of the MoHE in Syria, which is typically representing most Syrian key universities. It is also the prime university in terms of campus sustainability with no development of resource efficient campuses. Initiatives were centered on fostering SD by science and technology, management, and education. There were such projects funded by DU to generate green energy products as solar thermoacoustic refrigerator presented by Yassen in 2015 and applied in the newly developed part of the campus [45]. Currently, researchers in DU are planning for installation of other renewable energy technologies in more campus buildings.

Another dimension, the current study concentrates on the visions of sustainable futures dealing with transformation of not only technology but mindsets of professionals in all walks of life. DU continues its trends to take a leading role in the Syrian Green University Network (SGUN) launched and guided by education and construction authorities.

Nonetheless, the vision and the goals flowing from this research are ambitious but, can be reached, and will ensure the visibility of the green profile of DU campus by the year 2030. Realizing this vision will require the participation and cooperation of the entire university community and will transform DU into a healthier and safer place to work and study, a leader and role model in reduction of emissions, and the creator of leaders who solve national and/or world-wide environmental issues that threaten the planet.

The samples of this study composed of 100 participants selected from DU. Participants were chosen on the base of their current roles and experiences with campus construction and their thoughts about sustainability. The assortment criteria were:

i. Experience and knowledge in sustainability, particularly in a sustainable campus;

Table 1: Profile of interviewees.

\begin{tabular}{|c|l|l|c|}
\hline Letter & Department & Position & $\begin{array}{l}\text { No. } \\
\text { Interviewees }\end{array}$ \\
\hline A & Post-graduate Students & $\begin{array}{l}\text { Academic } \\
\text { Supervisors }\end{array}$ & 30 \\
\hline B & Managerial Offices & $\begin{array}{l}\text { Senior } \\
\text { Administrators }\end{array}$ & 13 \\
\hline C & Financial Department & Director & 1 \\
\hline D & Student's Union & Director & 1 \\
\hline E & $\begin{array}{l}\text { Development and planning } \\
\text { research office }\end{array}$ & Deputy Director & 1 \\
\hline F & DU Campus Office & Director & 5 \\
\hline G & $\begin{array}{l}\text { Campus Construction } \\
\text { Headquarter }\end{array}$ & Directors & 3 \\
\hline H & IT Office & Directors & 15 \\
\hline I & Campus Restaurant & Directors & 30 \\
\hline J & Campus Cleaning services & Undertakers & \\
\hline
\end{tabular}




\section{ii. A top-level position within his/her department; and \\ iii. A willingness to contribute to the research.}

The profiles of interviewees were described in Table 1. All interviewees had been directly involved in a sustainable campus project. Interviews conducted face-to-face encouraging free flowing discussion between the interviewees and the researcher. Each interview took approximately 2 hours, while, the first five minutes were spent on an introduction of the aims of this research.

The main interview questions were as follows:

1) What's your definition of the sustainable campus?

2) In your opinion, what key factors influence the development of the sustainable campus?

3) From these factors which is the most important factor? And why is that?

The main issues derived from that questionnaire were as follow:

a. The aim of campus development: Building upon the accessible efforts on resource efficient campus to promote sustainable campus construction. This enhances students' academic responsibilities to build green societies through their effective participations in institutes;

b. Priorities: Developing campus creative industry with renovated infrastructure of science and technological platforms;

c. Facilities: Enhancing energy conservation and the usage of the lower emission technologies, renewable energy sources application, and campus facility energy conservation management;

d. Intelligent campus: Digitalizing the public service platform;

e. Safe campus: Early warning mechanism and grid management mode;

f. Reform scheme: Enhancing the general education on SD, particularly in sustainable campus context; and

g. Infrastructure: Retrofitting old buildings; development of constructing land efficient new buildings, integration of solar PV and solar hot water system in buildings, and application of geothermal energy into swimming pools.

The in-depth interviews and the observations yielded a large number of qualitative data. These included: interview remarks (2 hours per dialogue) and document review notes. Critical documents review notes included:

- Solar power house application in DU;

- $\quad$ Future building: not only energy saved, but, also energy produced; and

- Low carbon economy and city development.

To examine the relative importance of various factors for campus sustainability, the evaluation system showed that there was a dominant or recessive interaction between indices. It was in fact a serious issue to analyze the interdependence factors among different levels of the framework when determining the weights of various indices. However, the ANP method is an effective approach to solve this issue. This is due to the fact that ANP measures all indirect interactions in a network, and takes all direct and indirect influences into account $[46,47]$.

\section{Findings via Case Study of DU - Interview Results Hard system}

Campus environment: According to interviewees A, a university campus improves working efficiency and ensures the happiness of stakeholders. This was also echoed by interviewees $\mathrm{B}$ and $\mathrm{H}$, who stated that the campus environment has a great influence on both study and working, as well as on the long-term development of the university.

The majority of interviewees nominated consumption of all kinds of energy resources as one of the most vital factor for campus sustainability. According to interviewees, campus greening, sanitary conditions and pollution control are critical for creating and sustaining an appropriate campus environment. Interviewees A, $\mathrm{B}$, and $\mathrm{H}$ pointed out that campus greening helps to improve not only the landscaping, but, also air quality and subsequently requires continuous attention.

Interviewees $\mathrm{B}, \mathrm{D}, \mathrm{I}$, and $\mathrm{J}$ acknowledged that the sanitary conditions not only affect the appearance of the university, but, also the health of staff and students. They stressed on the sanitary conditions in campus construction otherwise will pose great risk to students' and staffs' health, and damage the reputation of campus. In addition, the pollution condition is an obvious indicator of the campus environment (interviewees A), and pollution control measures of a campus can show the extent of its sustainable technology (interviewee E). Interviewees E, F, G, and J revealed that campus environmental issues are considered in a number of projects, e.g. wastewater collection, retreatment and reuse in arid lands which could be implemented in a water recycling project in DU campus. For instance, it is expected the water recycling measures in DU campus will help to save 400,000 tones of water every year.

Facilities: According to interviewees (10\%), the building site, building energy condition and construction costs are important factors. The building site means a campus can take the future development into account (interviewee $\mathrm{E}$ and G). Those interviewees revealed that there are a number of initiatives lowers the energy use and makes the campus more sustainable. The construction costs do not presume the lowest charge and cheap materials but the best price ratio of a campus building (interviewee $\mathrm{C}$ ). This is also supported by interviewees $\mathrm{H}$ by stating "sometimes, we'd better spend more money on those environmental materials and structures, instead of pursuing the cheapest one".

In addition, interviewees $\mathrm{G}$ suggested that building materials and innovative design should be considered as well. They further explained that low - impact materials may decrease the embodied energy, waste and emissions throughout the construction process in campus. Other examples include solar water heater system for students' shower facilities, geothermal heat pump, green roof and electrical thermal storage boiler. In addition, no water is drawn from tap water sources for irrigation purposes on campus and all new-built buildings comply with the national design standard for building energy efficiency.

Campus planning: Campus planning is essential for the campus's 
future in the next several years or even several decades (interviewee C). Interviewees from A (10\%), B (15.4\%), E, and F suggested that the distribution of land use should be a factor. Notably, it is echoed by interviewee E's suggestion: "a reasonable master plan needs to facilitate sustainable university development". Interviewee E also mentioned that the campus could still accommodate more buildings in the coming decades.

In addition, sixty interviewees: A (100\%), B (100\%), C, D, E, F, G (100\%), $\mathrm{H}(33.3 \%)$, and $\mathrm{J}(26.7 \%)$ considered the transportation and planning, while four interviewees nominated the capital investment priorities. According to interviewees B (23.1\%) and D, a well-planned transportation network provides convenience to staff and students while the benefits related to reducing time in transportation improves the efficiency in scientific research and bonding various campuses. However, 56 interviewees: A (20\%), B (100\%), C, D, E, F, G (100\%),
$\mathrm{H}(33.3 \%)$, I (20\%) and J (80\%) agreed that the capital investment priorities are largely depending on the leaders' decision, which will be analyzed in leadership resolution.

\section{Soft system}

Campus management: Interviewees B commented that it is important to develop the managerial plans of the campus so as the concept of sustainability can be promoted. The effective and efficient management plans have great influence on a campus's development (interviewees B, C and E).

Seventy interviewees: A (23\%), B (100\%), C, D, E, F, G (100\%), $\mathrm{H}(100 \%), \mathrm{I}(20 \%)$ and J (63.3\%) stated that the sustainable campus needs a sound management system. An effective management system could improve the efficiency of the entire university system and may conserve resources which ease the achievement of the sustainability

Table 2: Evaluation system framework of sustainable campus.

\begin{tabular}{|c|c|c|c|}
\hline Goal & Type & Main factors & Detailed factors \\
\hline \multirow{41}{*}{$\begin{array}{l}\text { Sustainable campus } \\
\text { factors }\end{array}$} & \multirow{14}{*}{ Hard system construction } & \multirow{5}{*}{ Campus environment } & Campus greening \\
\hline & & & Campus sanitary conditions \\
\hline & & & Pollution conditions \\
\hline & & & Pollution control measures \\
\hline & & & Energy use \\
\hline & & \multirow{9}{*}{ Facilities } & Building site \\
\hline & & & Water efficiency in building \\
\hline & & & Building energy use \\
\hline & & & Building energy savings \\
\hline & & & Utilizations of renewable energy \\
\hline & & & Building materials \\
\hline & & & Indoor environmental quality \\
\hline & & & Innovative building design \\
\hline & & & Construction costs \\
\hline & \multirow{9}{*}{ Soft system construction } & \multirow{3}{*}{ Campus planning } & Distribution of land use \\
\hline & & & Capital investment priorities \\
\hline & & & Transportation planning \\
\hline & & \multirow{4}{*}{ Campus management } & Management system \\
\hline & & & Oversight mechanisms \\
\hline & & & Censorship system \\
\hline & & & Management of students \\
\hline & & \multirow{2}{*}{ Leadership } & Emphasis on sustainable campus \\
\hline & & & Leaders' vision on sustainability \\
\hline & \multirow{18}{*}{ Mixture of hard and soft systems } & \multirow{10}{*}{ Human resource development } & Awareness of sustainability \\
\hline & & & Sustainability oriented courses \& seminars \\
\hline & & & Promotion of sustainability \\
\hline & & & Behavior of teachers \& students \\
\hline & & & International education \\
\hline & & & Meet the experiment and research needs \\
\hline & & & Staff quality \\
\hline & & & Specialty arrangements \\
\hline & & & Outcomes of teaching and scientific research \\
\hline & & & Accommodation for young staff \\
\hline & & \multirow{4}{*}{ Campus safety } & Personal safety \\
\hline & & & Property safety \\
\hline & & & Traffic safety \\
\hline & & & Handling of emergencies \\
\hline & & \multirow{4}{*}{ Logistic support } & Satisfaction level to accommodation \\
\hline & & & Diet and food recycling \\
\hline & & & Logistic management \\
\hline & & & Information service platform \\
\hline
\end{tabular}


Table 3: Results of factors' weights.

\begin{tabular}{|c|c|c|c|c|}
\hline Main factor & Main factor weights & Detailed factors & Relative weights & Global weight [46] \\
\hline \multirow{10}{*}{ Campus Environment } & \multirow{10}{*}{0.2757} & Accommodation to young staff & 0.1049 & 0.0037 \\
\hline & & Campus greening & 0.0981 & 0.0270 \\
\hline & & Campus sanitary conditions & 0.0365 & 0.0101 \\
\hline & & Energy use research needs & 0.1867 & 0.0515 \\
\hline & & Outcomes of teaching and scientific research & 0.0654 & 0.0023 \\
\hline & & Pollution conditions & 0.2893 & 0.0798 \\
\hline & & Pollution control measures & 0.3894 & 0.1074 \\
\hline & & Specialty arrangements & 0.3235 & 0.0115 \\
\hline & & Staff quality & 0.0930 & 0.0033 \\
\hline & & \multicolumn{3}{|l|}{ C. R. $=0.0340$} \\
\hline \multirow{5}{*}{ Campus Safety } & \multirow{5}{*}{0.0432} & Handling of emergencies & 0.2640 & 0.0114 \\
\hline & & Personal safety & 0.5252 & 0.0227 \\
\hline & & Property safety & 0.0861 & 0.0037 \\
\hline & & Traffic safety & 0.1247 & 0.0054 \\
\hline & & \multicolumn{3}{|c|}{ C. $R .=0.0533$} \\
\hline \multirow{4}{*}{ Logistics } & \multirow{4}{*}{0.0396} & Diet and food recycling & 0.5171 & 0.0205 \\
\hline & & Logistic support & 0.2355 & 0.0092 \\
\hline & & Information service platform & 0.0999 & 0.0040 \\
\hline & & \multicolumn{3}{|c|}{ C. R. $=0.0221$} \\
\hline
\end{tabular}

Table 4: Values of R.I.

\begin{tabular}{|l|c|c|c|c|c|c|c|c|c|c|}
\hline $\mathbf{N}$ & 1 & 2 & 3 & 4 & 5 & 6 & 7 & 8 & 9 \\
\hline R.I. & 0 & 0 & 0.58 & 0.90 & 1.12 & 1.24 & 1.32 & 1.41 & 1.45 & 1.49 \\
\hline
\end{tabular}

goal (interviewees G).

Other factors related to campus management include oversight mechanisms and censorship systems for the implementation of campus sustainability activities, e.g. finance (interviewee C).

Interviewee $\mathrm{F}$ asserted that many policies cannot be executed properly without oversight mechanisms on campus. Interviewees A discussed this issue from the student's point of view, suggesting that the university could place more emphasis on students, in order to standardize student's administration.

\section{A Vision to the Future with Sustainability}

In DU, a dedicated committee to a resource efficient campus can be established with the vice president acting as the director (Figure 2). Under his/her leadership, an administration office is responsible for day-to-day activities related to campus sustainability. Members of this office come from functional departments such as: energy centre, logistics department, capital construction department, and asset department with the involvement of the student union. This is supported by a group of experts that are appointed for providing professional advice on various sustainability issues such as: building material, ventilation, and architectural planning.

\section{Leadership}

The leaders of the university play a decisive role (interviewee F). Leadership determines the macro- development direction of a university, such as: the capital investment priorities, campus planning, etc. (interviewee F).

According to the interviewees, the attitude and vision of university leaders are crucial to attain campus sustainability. Interviewee E used a metaphor to describe this: "campus is similar to a big machine, and the leaders are its manipulators. What they think and what they decide will directly affect the campus development". Taking DU as an example, the top management brings great importance to sustainability so that the campus can develop sustainability.

\section{Campus culture}

Campus culture has a potential effect on students and staff in the campus and may not perceive in a short-term (interviewees A).

The stakeholder's awareness of sustainability appealed more to the interviewees. This may be related to the culture within the society (interviewees J). Whether staff and students on campus realize the importance of sustainability but they will definitely affect the whole

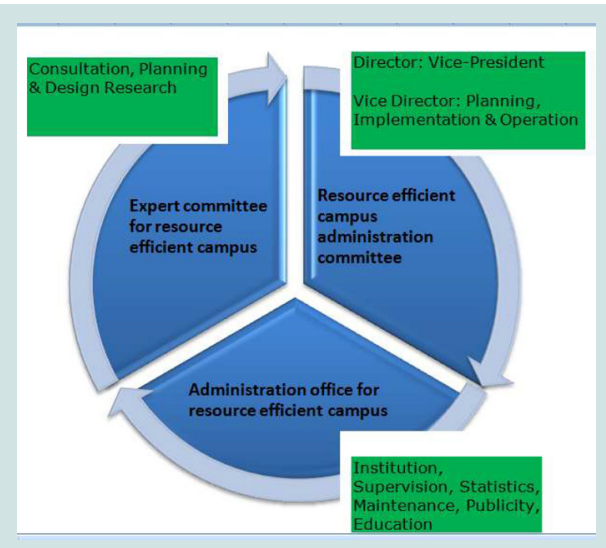

Figure 2: Governance of campus sustainability of University of Damascus. 


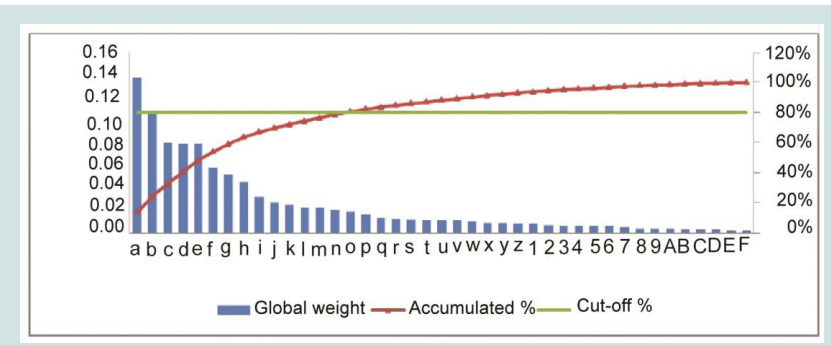

Figure 3: Pareto chart of factors weight.

Factors: a - Distribution of land use, b - Pollution conditions, c - Pollution controls, $d$ - Water efficiency in buildings, e - Leader's vision on sustainability, $\mathrm{f}$ - Management system, $\mathrm{g}$ - Energy system, $\mathrm{h}$ - Awareness of sustainability, i - Capital investment priorities, $\mathrm{j}$ - Campus greening, $\mathrm{k}$ - Campus system, I Censorship system, $\mathrm{m}$ - Diet and food safety, $\mathrm{n}$ - Personal safety, $\mathrm{o}$ - Oversight mechanisms, $p$ - Utilization of renewable energy, $q$ - Emphasis on sustainable campus, $r$ - Indoor environmental quality, $s$ - Building's location, $t$ - Specialty arrangements, $\mathrm{u}$ - Energy and atmosphere, $\mathrm{v}$ - Handling of emergencies, w Promotion of sustainability, $x$ - Campus sanitary conditions, $y$ - Construction costs, $\mathrm{z}$ - Meet the experimental research needs, 1 - Transportation planning,

2 - Building energy use, 3 - Building materials, 4 - Innovation and design, 5 - Satisfaction level to accommodation, 6 - Logistic management, 7 Traffic safety, 8 - Property safety, 9 - Accommodation for young staff, A Management of students, B - Staff quality, C - Information service platform,

D - Sustainability oriented courses and seminars, E - Behavior of teachers and students, F - Outcomes of teaching and research.

atmosphere of the campus and influence its sustainable construction (interviewees G). In another word, the awareness is one of the most difficult things to change and to cultivate (interviewees A). In addition, interviewee $\mathrm{D}$ suggested that more sustainability oriented courses and seminars shall be provided so that students can deepen their understanding of SD.

The attitude of staff and students is important as well. The degree of sustainability of a campus can be gauged through the daily work of staff and students. Interviewee $\mathrm{C}$ stated that: "sometimes tiny things, such as wasting a small piece of paper or forgetting to turn off the lights will affect the sustainability of the university". Interviewees A agreed with this but also emphasized that the sustainability attitude of staff and students cannot be improved immediately and may take a very long period of time.

\section{Mixture of hard and soft systems}

Human resource development: Interviewee E emphasized that one of the core functions of the university was to educate students so that they could invest their basic learning in the society. This was supported also by interviewee D stating that students gained up-todate knowledge and skills, in particular problem-solving skills to tackle rising concerns as on climate change. The methods suggested by interviewees include: setting up reasonable specialties, supporting experiment, and research needs or internationalization through Exchanging Overseas Students Programs to broaden their horizons and learning advanced technologies. A university should offer students a broad platform, so that students have access to sustainable education (interviewees A, D, E, and F).

Campus safety: Safety on campus is another important factor. Accidents or crimes may not happen frequently on campus, but may create significant negative impacts on the university, especially in its SD.
Campus's Security Department in DU has taken some measures to provide campus protection which includes personal safety, property safety, and traffic safety and handling of emergencies (interviewee F).

Logistic support: Most interviewees suggested increasing reasonable accommodations to the student's daily life which is an important systematic and transparent factor. In addition, some interviewees emphasized on diet and food recycling (interviewees A and $\mathrm{D}$ ), which had also taken into consideration by the information service platform (IT department), and formed two aspects of logistic support. The directors of the IT departments revealed that the information service platform is a comparatively new concept in Syria needs continuous improvement. These factors were summarized in Table 2.

\section{Results of ANP}

Based on the evaluation system framework of a sustainable campus in Table 3 that shows the determined weights of factors, a questionnaire survey was conducted with interviewees to investigate the degree of perceived importance of these factors.

\section{Consistency test}

Based on the principle of ANP, authors used random consistency ratio (C.R.) to test the consistency of judgment matrix. C.R. and C.I. are ruled in equations ( 1 and 2$)$ :

$$
\text { C.R. }=\text { C.I. } / \text { R.I. }
$$

In which,

$$
\text { C.I. }=\left(\lambda_{\max -\mathrm{n})} /(\mathrm{n}-1)\right.
$$

Where:

$n$ : the order of the matrix of hierarchies.

$\lambda$ : the eigen value of the matrix. The maximum value of $\lambda$ is expressed by " $\lambda_{\max }$ " extracted from Expert Choice Software [46].

\section{R.I.: The average Random Index for consistency checking.}

\section{C.I.: The consistency index for each matrix}

Only when the C.R. is less than 0.1 we can determine that the weights matrix passes the consistency test [48]. In Table 3, the values of C.R. were all less than 0.1 , which meant the weights of the factors could pass the consistency test.

As shown in Table 3, pollution controls, specialty arrangements, personal safety, diet and food recycling were ranked top in each category. However, in terms of global ranking, pollution control measures, pollution conditions, personal safety, and satisfaction level to accommodation were perceived as most important factors for campus sustainability.

\section{Discussion}

DU addresses issues related to both of the environment and climate, and their relations to architecture. Some schools in this university introduce the technical and technological aspects without adequate reference to environmental concerns and the protection of natural resources. The terms "sustainability, SD, green design, ecological design, and sustainable design practices" did not appear 
in any of the course titles or course descriptions of any of the DU schools, even their underlying concepts vary in each school. The socio-culture was not even considered with a notable interest in economic/environmental domain. These courses rarely referred to the environmental context within the region or the locality. In fact, they most often only referred to the advanced technology of the western world thus making such courses effectively irrelevant within the context of the actual environmental concerns in DU. These findings were opposite to the corresponding observations of the American University of Beirut that provides current information and knowledge which form the backbone of certain courses offered as electives or specialist subjects. These courses focus on inculcating the importance of developing sustainability and environmental consciousness. Hence, DU administration should commit to establishing practices to conserve energy as well as decrease the university's carbon footprint.

Based on the global weights shown in Table 3, a Pareto chart was drawn (Figure 3). As shown in Figure 3, the accumulative percentage of top 15 factors reached $80 \%$. These factors were: distribution of land use, pollution control measures, pollution conditions, water efficiency in buildings, leaders' vision on sustainability, management system, energy use, awareness of sustainability, capital investment priorities, campus greening, censorship system, diet and food recycling, personal safety, oversight mechanism, and utilization of renewable energy. These 15 factors were attributed to campus sustainability by experts.

The top ranking factor for campus sustainability is the land use decision. This is arguably due to the fact that major cities in Syria are experiencing challenges of land resources as a result of rapid urbanization or/and relocation, and immigration. This obstructs the sustainability of urban planning as one of the most recent critical issues with the absence of effective working methods and proper investment of greener procedures [49].

In Syria, some of the universities were built and relocated to new campuses in suburban or regional areas to accommodate the growing number of students apart from coping land use pressure. A proper utilization of limited land resources is not possible without sustainability oriented strategic vision of the university which is also linked to priorities of capital investment. Indeed, land use and planning as a sustainability commitment should continuously be monitored.

To realize the environmental sustainability orientation in campuses, experts clearly showed emphasis on environmental aspects of campus sustainability with about half of the top 15 factors. Among these factors, pollution conditions and pollution control measures were ranked as $2^{\text {nd }}$ and $3^{\text {rd }}$ respectively. The pollution associated with campus operation is a common issue which has globally attracted attentions [17]. To deal with this issue, EMS is an effective approach herein [50]. In addition, the utilization of renewable energy helps to reduce the environmental burden due to conventional fossil fuels. Similarly, water efficiency should be improved by means of both technologies and behavioral change [51].

Social sustainability was recognized as well with personal safety as one of top 15 factors for campus sustainability that links to food and water safety, and laboratory safety. DU authority is recommended to extend the representation of socio - culture courses which may include man-environment relations, rural geography, and rural sociology. They can get the benefits from the Turkish expertise in the Middle-East Technical University that emphasizes on courses pertain to restoration and conservation as processes of building/urban recycling and adaptive reuse of the built heritage [52].

Therefore, Management and Leadership are important for campus sustainability as well with multiple factors ranked Top 10 . These warrant further research whether or not relating to:

(1) the recent development of SGUN; and

(2) the endorsement of Rio + 20 Declaration.

According to the Pareto chart, compared to the other factors, some may not catch emphasis at this time. These factors are: staff quality, sustainable oriented courses and seminars (i.e. environment-behavior studies as adopted by Cairo University and Al-Azhar University in Egypt), and outcomes of teaching and scientific research [52]. All of these were related with talents and students training, which were also in line with the current strategy of Syrian education. These factors are important since teaching is impetuous and pursues more profits than academic achievements. Despite, the sustainability campus construction in Syria is still at the first level. The leaders of campus care more about hard system than soft one. Sustainable campus not only means the sustainable in environment or buildings, but also in talents and students training, where the benefits from may not be seen abruptly [39]. This kind of concept has gradually permeated into the higher education sector in Syria.

A sustainable campus provides a base of talents, and that's why universities should try hard to retain talents (interviewees E, F and $\mathrm{H})$. Plus that meets with what interviewees $\mathrm{H}$ quoted in common: "a sustainable campus should also place an emphasis on its staff quality and students training". The construction of labs and other research facilities should also meet the needs of both academics and student requirements. In addition, university should aim for providing sustainable oriented curricula. That means: sustainable campus is much more than setting out recycling bins across campus. Faculties have to charge with the finding methods to integrate sustainable education within their courses. Moreover, new construction and renovation campus should use sustainable materials. Further new degrees may involve the bachelor of integrated studies with an emphasis in sustainability, society and resource management.

To transform the DU campus into a greener institution, the suggested practices by this study may introduce new requirements to these curricula and teaching staff's skill sets. The new education system can be made permanently after the finish of the project which must prove the effectiveness under Syrian conditions. Educating the educators is critical for SD in higher education. Teachers support students to design manageable and achievable actions for sustainability, so that sustainability principles can be better incorporated into curricula [9].

As a result of globalization, competitiveness and accelerating expansion of private higher education, it is vital for DU campus management to take several actions such as:

1. From brain drain to brain gain - To work on devising good 
and positive practices to curb the brain drain losses especially during the war in Syria since 2011. These are due to the political instability, social injustice, absence of appropriate environment to conduct research, lack of research facilities and low quality research standards, lack of freedoms, low salaries, and lack of work motivations and incentives;

2. To tackle the ineffective cooperation and coordination with other Syrian universities, especially with a proper exchange of information, experiences, publications, and co-research especially in the fields of energy, environment, health sciences, and information and communication technology;

3. To tackle the inflation of students' number and the limited number of available staff members which direct effects on the current DU quality of education;

4. Taking from successes of some regional experiences to transfer Damascus University Journal to the international high ranks journals as the Iranian Journals (Iranian Journal of Radiation Research, Journal of Environmental Studies, International Journal of Environmental Science and Technology, Iranian Polymer Journal, Iranian Journal of Fuzzy Systems, Journal of Applied Fluid Mechanics) and the Saudi Arabia Journal (Economist Magazine);

5. To increase the insufficient rates of expenditures on scientific research $(\$ 100-\$ 2000)$;

6. To increase the outputs of scientific research in compliance with the implementation of a national policy or a clear strategic plan in this field;

7. To develop the traditional scientific research of students that tackles the socio-economic aspects;

8. Going to the market to activate the partnership with industry and redirect the pointer of the economic projects to link the production sector and the industrial facilities;

9. To connect the scientific research with the national sustainable development plans;

10. To embed sustainability across the university policy and practice, particularly in teaching and learning;

11. To develop continuing professional development (CPD), pedagogic research, resource development, hybrid learning space design, whole institutional change, and critical perspectives on the field of ESD. These are assigned to support student engagement for instance to recycle more Waste Electrical \& Equipment (WEEE) on Campus;

12. To improve the DU quality assurance frameworks and develop the current established ones in order to guarantee the persistence of the quality of education and control its outcomes;

13. To develop, enhance and review current internal quality management systems;

14. To work with other national programs to establish local quality assurance network to help promoting QA of higher education in DU and the other national partners;

15. To build effective capacities for education quality assurance systems;
16. To develop action plans on quality assurance of higher education institutions in DU;

17. To guarantee a high quality precision for higher education institutes in DU;

18. To enhance international cooperation in fields of higher education quality assurance;

19. To corporate with national accreditation bodies to discuss and plan together in order to create a Syrian umbrella to take the responsibility of quality assurance, while making all the efforts with UNESCO and relevant organizations, to give effect to the Convention on the Recognition of Studies, Certificates, Diplomas, Degrees and other Academic Qualifications in Higher Education in the region to ensure promoting academic mobility and strengthening international understanding; and

\section{To establish a Centre for Sustainable Futures in DU.}

Empirically, this study provides decision makers of the higher education sector with relevant information regarding the intended future attempts to reform the university greener policy. DU sustainable campus is based on the core of the triangle education-researchinnovation. Sustainability in Education is no longer preparation for an assumed stable future not even for the current situation in Syria but a nurturing of individuals and collective potential to live well and skillfully in an already complex and volatile world. However, the effect of the investment in sustainable campus may not appear immediately, which may need even more than one generation's great efforts.

\section{Conclusions}

A series of studies have been undertaken to investigate sustainable development in universities. However, there were very limited trials in a Syrian context. In spite of that, the results of this work proved that there is a growing awareness on sustainability issues associated with the higher education sector. The candidates of this study have concerned the education about, in, and for the environment.

A number of factors related to campus sustainability were identified in this study by means of semi - structured interviews. As shown in Table 3, this comprehensive framework covered major components of existing evaluation systems in Syria as the Resource Conservative Campus Evaluation Standard.

Additional factors were identified in this study as campus sanitary conditions and information service platform. On the other hand, the leadership on sustainability and safety on campus merged as groups of key factors in this study were not covered in the evaluation process.

Compared to the leading international campus sustainability systems as the College Sustainability Report Card, this framework provides a similar structure [16]. However, differences were obvious. For instance, the SEI system enclosed the endowment transparency and shareholder engagement that were out of the scope of this study. Both systems covered investment priorities, however, the SEI framework placed a large focus on return on investment which was not considered as a key factor in this study. Similarly, the SEI system involves very detailed indicators for management aspects of campus sustainability, e.g. publicity, human resources dedicated for 
sustainability, formal sustainability policy or action plan. This study identifies similar factors; yet, these are assigned to different categories such as: campus management and leadership. Indeed, these refer to a gap between campus sustainability practices in Syria and leading practices elsewhere.

Similarly, the relative importance of these factors was sought by means of a questionnaire survey followed by the ANP analysis. As shown in Table 3, the Campus Environment, Campus Planning and Campus Management factors received higher weights whereas Campus Culture, Human Resource Development and Logistics Support received comparatively lower weights. These findings provide a useful reference to both government authorities and universities to effectively implement campus sustainability initiatives. In addition, these may contribute towards urban and regional sustainability due to the significant role of the higher education sector in the system. The identification of these key factors and their weightings provide useful inputs to the future endeavor of assessing campus sustainability. The weights of the factors can be identified through building a structure equation model or data envelopment analysis.

Subsequently, DU sustainable education needs to become more responsive to the paradigmatic trends of interest to the international community. It must adapt knowledge components derived from these trends to the local context and the scientific norms defined by the culture, environment and technology.

\section{References}

1. Mcmillin J, Dyball R (2009) Developing a whole-of-university approach to educating for sustainability linking curriculum, research and sustainable campus operations. J Educ Sustain Develop 3: 55-64.

2. Karatzoglou B (2013) An in-depth literature review of the evolving roles and contributions of universities to education for sustainable development. J Clean Prod 49: 44-53.

3. Adomßent M (2013) Exploring universities' transformative potential for sustainability-bound learning in changing landscapes of knowledge communication. J Clean Prod 49: 11-24.

4. Croog $R$ (2016) Campus sustainability at the edges: emotions, relations, and bio-cultural connections. Geoforum 74: 108-116.

5. (2015) Project-level sustainability initiatives. In: Yates JK, Castro-Lacouture D (Eds), Sustainability in engineering design and construction, CRC Press, Taylor and Francis Group, Boca Raton, New York, USA, pp. 159-166.

6. Waas T, Verbruggen A, Wright T (2010) University research for sustainable development: definition and characteristics explored. J Clean Prod 18: 629636 .

7. Norazah MS, Norbayah MS (2016) Campus sustainability: does student engagement with eco-campus environmental activities and green initiatives really matter? In: Filho WL, Brandli L (Eds), Engaging stakeholders in education for sustainable development at university level. World Sustainability Series, Springer International Publishing, Switzerland, Europe, pp. 45-49.

8. Green Campus Committee, China Green Buliding Council (2009) Resource conservative campus evaluation standard, the green campus committee of the China Green Building Council.

9. Lozano-García FJ, Huisingh D, Delgado-Fabián M (2009) An interconnected approach to incorporate sustainable development at tecnológico de monterrey. Int J Sustain High Educ 10: 318-333.

10. Brown BC (2005) Theory and practice of integral sustainable development an overview. Part 1: Quadrants and the practitioner. AQAL J Integral Theory Pract 1: 2-36.

11. Schild R, Clark C (2010) An integral approach to institutionalizing sustainability in higher education: a case study of Colorado College. PhD Thesis, Duke University, Durham, North Carolina, USA.

12. Jabbour CJ (2010) Greening of business schools: a systemic view. Int $J$ Sustain High Educ 11: 49-60.

13. Brown K, Shephard K, Warren D, Hesson G, Fleming J (2016) Using phenomenography to build an understanding of how university people conceptualise their community-engaged activities. High Educ Res Dev 35: 643-657.

14. Alshuwaikhat HM, Abubakar I (2008) An integrated approach to achieving campus sustainability: assessment of the current campus environmental management practices. J Clean Prod 16: 1777-1785.

15. Barata E, Cruz L, Ferreira JP (2010) Parking Problems at the UC campus: setting the research agenda. 12th WCTR, Lisbon, Portugal.

16. Sustainable Endowments Institute (2011) The college sustainability report card.

17. Emanuel R, Adams JN (2011) College students' perceptions of campus sustainability. Int J Sustain High Educ 12: 79-92.

18. Kibert CJ (2013) Sustainable construction: green building design and delivery. Intell Build Int 5: 65-66.

19. Finlay J, Massey J (2012) Eco-campus: applying the ecocity model to develop green university and college campuses. Int J Sustain High Educ 13: 150-165.

20. Bero BN, Doerry E, Middleton R, Meinhardt C (2012) Challenges in the development of environmental management systems on the modern university campus. Int J Sustain High Educ 13: 133-149.

21. Yekkalar M, Panahi S, Nikravan M (2015) Evaluation of current laboratory waste management: a step towards green campus at Amirkabir University of Technology. In: Filho WL, Muthu N, Edwin G, Sima M (Eds), Implementing campus greening initiatives: approaches, methods and perspectives. World Sustainability Series, Springer International Publishing, Switzerland, Europe, pp. 215-227.

22. Mitchell RC (2011) Sustaining change on a Canadian campus: preparing Brock University for a sustainability audit. Int J Sustain High Educ 12: 7-21.

23. Currier KM (2015) Some implications of investment cost reduction policies in energy markets employing green certificate systems. Environ Resour Econ 60: 317-323.

24. Kalkan N, Bercin K, Cangul O, Morales MG, Saleem MM, et al. (2011) A renewable energy solution for highfield campus of University of Southampton. Renew Sust Energ Rev 15: 2940-2959.

25. Al-Zubaidy MS (2015) A literature evaluation of the energy efficiency of leadership in energy and environmental design (LEED) - Certified buildings. Am J Civ Eng Archit 3: 1-7.

26. Cole L (2003) Assessing sustainability on Canadian University campuses: development of a campus sustainability assessment framework. MSc thesis, Royal Roads University, Victoria, Canada.

27. Ashwini S, Judy W, Margo W (2014) Higher education sustainability in Pittsburgh: highlights from the AASHE 2011 campus tours. AASHE insights 1: 39-59.

28. Lukman R, Glavič $P$ (2007) What are the key elements of a sustainable university? Clean Technol Environ Policy 9: 103-114.

29. Rickards S, Howitt R, Suchet-Pearson S (2014) Ecological footprinting as a top-down and bottom-up approach to complete campus engagement and transformation towards the one planet goal. In: Filho WL, Brandli L, Kuznetsova O, Paco AM (Eds), Integrative approaches to sustainable development at university level: making the links. World Sustainability Series, Springer International Publishing, Switzerland, Europe, pp. 43-66.

30. Mbah MF (2016) Towards the idea of the interconnected university for sustainable community development. High Educ Res Dev 1-14.

31. Sarah $L$ (2008) Green campus an analysis of the factors that drive universities to adopt sustainable practices. College of William and Mary, Virginia, USA. 


\section{ISSN: $2471-4879$}

32. Too L, Bajracharya B (2015) Sustainable campus: engaging the community in sustainability. Int J Sustain High Educ 16: 57-71.

33. Jain S, Pant P (2010) Environmental management systems for educational institutions: a case study of TERI University, New Delhi. Int J Sustain High Educ 11: 236-249.

34. Chang HC (2013) Environmental management accounting in the Taiwanese higher education sector: issues and opportunities. Int J Sustain High Educ 14: 133-145.

35. Brinkhurst M, Rose P, Maurice G, Ackerman JD (2011) Achieving campus sustainability: top down, bottom up, or neither? Int J Sustain High Educ 12: 338-354.

36. Mulder KF, Segalàs J, Ferrer-Balas D (2012) How to educate engineers for/in sustainable development: ten years of discussion, remaining challenges. Int J Sustain High Educ 13: 211-218.

37. Rands GP (2009) A principle-attribute matrix for environmentally sustainable management education and its application: The case for change-oriented service-learning projects. J Manag Educ 33: 296-322.

38. Lüdeke-Freund F, Burandt S (2010) Universities as learning organizations for sustainability? the task of climate protection. In: Filho WL (Ed.), Universities and climate change: introducing climate change to university programmes. Springer-Verlag Berlin Heidelberg, Germany, pp. 179-192.

39. Hall OP, Mooney JG (2010) Hybrid learning systems: meeting the challenges of graduate management education. In: Tsang P, Cheung SK, Lee VS, Huang $\mathrm{R}$ (Eds), Hybrid Learning, Lecture Notes in Computer Science, Springer Berlin Heidelberg, New York, USA, pp. 35-48.

40. Alshahrani K, Ally M (2016) Transforming education in the gulf region: emerging learning technologies and innovative pedagogy for the $21 \mathrm{st}$ century. Routledge Research in education, CRC Press, Taylor and Francis Group, Boca Raton, USA, pp. 98-109.

41. Dorte V, Robert W, Clemens B, Perrihan A, Richard R, et al. (2013) Tunisia in a changing climate: assessment and actions for increased resilience and development. A World Bank study, Washington, USA

42. Bell S (2016) Sustainable distance learning for a sustainable world. Open Learning 31: 1-8.

43. Ramadan R (2016) Syrians' acceptance of digital lectures: a case study. Open Learning 31: 9-24.

44. Chen P, Partington D, Wang JN (2008) Conceptual determinants of construction project management competence: a Chinese perspective. Int J Proj Manag 26: 655-664.

45. Yassen N (2015) Impact of temperature gradient on thermoacoustics refrigerator. Energy Procedia 74: 1182-1191.

46. Lee H, Kim C, Cho H, Park Y (2009) An ANP-based technology network for identification of core technologies: a case of telecommunication technologies. Expert Syst Appl 36: 894-908.

47. Wan H, Sahasrabudhe AM, Rivera L (2014) Prioritization of lean tools using gap analysis and analytic network process [ANP]. Syst Telematics 12: 9.

48. Saaty TL (2006) The analytic network process - dependence and feedback in decision - making. Business Application and Computational Intelligence, RWS Publications, Pittsburgh, Pennsylvania, USA, pp. 360-387.

49. Maya RA (2010) Urban planning in Syria and its modern directions towards sustainable urban development. Damascus University J 26: 269-295.

50. Clarke A, Kouri R (2009) Choosing an appropriate university or college environmental management system. J Clean Prod 17: 971-984.

51. Davis G, O'Callaghan F, Knox K (2009) Sustainable attitudes and behaviours amongst a sample of non-academic staff: a case study from an Information Services Department, Griffith University, Brisbane. Int J Sustain High Educ 10: 136-151.

52. Salama AM (2015) Spatial design education: new directions for pedagogy in architecture and beyond ( $1^{\text {st }}$ edn.), Ashgate Publishing Ltd, Taylor and Francis Group, Surrey, England, pp. 416. 